\title{
Aesthetics in Young Children's Lives: From Music Technology Curriculum Perspective
}

\author{
Chia-Hui Ko
}

Mei-Ju Chou*

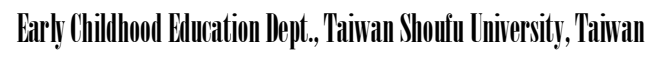

\begin{abstract}
Music technology is a term commonly used to refer to electronic form of the musical arts, particularly devices and computer software that enable the facilitation, playback, recording, composition, storage, and performance of various musical compositions. There has been a growing awareness of the importance of aesthetics in early childhood education, especially for the music technology that offers young children benefits from the implementation of an appropriately complete music technology curriculum in the early childhood educational environment and instruments application. The findings in this paper demonstrate such music courses encourage creativity and foster a sense of cultural understanding and appreciation amongst children in an early education program. In short, with the progress of developmentally appropriated program, this study demonstrates that music technology curriculum is not only valuable, but essential to the early education program for young children.
\end{abstract}

Keywords: Music Technology Curriculum, Early Childhood
Education, Aesthetics, creativity, Character
Education, fine arts

When people think of early childhood education, they typically navigate towards the consideration of reading, writing and arithmetic. While, these core academic areas are certainly the pillars of educational necessities for children, one needs to also consider the fine arts as another area that contributes greatly to the cognitive development of an individual. One such outlet of creative expression is music. In addition, technology has enhanced the way that music can be integrated into other disciplines, making this particular area even more worth to study.

Simply, music technology curriculum is composed of different types of technologies that

Manuscript received July 31, 2013; revised October 18, 2013; accepted November 25, 2013.

*Corresponding author Email: scholarate@gmail.com are directly related to the musical arts. This usually entails the use of various electronic devices, combined with computer software that allows the playback, recording, composition, storage, analysis and performance of any given piece (Branscome, 2012). While, this particular curriculum can be implemented at any grade level, all the way through the university, our primary focus in this study will be on early childhood education. In particular, this paper will examine the effects that music technology curriculum has on the learning development of young children.

\section{LITERATURE REVIEW}

While technology is rapidly changing nowadays, the concept of music technology has been 
International Journal of Management, Economics and Social Sciences

around since the 1980' s. The concept can be interconnected across disciplines because of its focus on artistic and technological creativity in many realms (Andang' o and Mugo, 2007; Barbot and Lubart, 2012). Young children can be taught music to express themselves through the arts, and technology has expanded in recent decades to create new devices to enable them to do just that. In essence, music technology can be said to encompass the scientific aspect of music that many individuals never consider. These components, when properly implemented in a music technology curriculum, can have an enormous and positive effect on young children (Hoffman, 1991).

Importance, Value and Current Development of Music Technology Curriculum

In order for any component of a fine arts program to remain a viable part of the curriculum, it needs to demonstrate that it is of value to the overall development of the child. In this age of shrinking budgets, and with more and more programs vying for those limited funds, it is more important that the music technology curriculum is comprised of components that have been shown to be of great importance to young children (Berry and Allen, 2002; Church, 2001). The first proposition, therefore, is that the early childhood music technology curriculum is important and of great value to the cognitive and creative development of children.

From ancient times, we know that music has been a basic part of human nature and culture (Church, 2001). On one level, it is a creative and individualistic form of communication. Children and adults alike can use music to express feelings and their own viewpoints on a variety of life experiences (Hoffman, 1991). Furthermore, music technology provides an opportunity for children to develop their own sense of imagination, and it allows them to show their inventive, sensitive and enjoyable nature. In short, music technology is much more than simply rhythm and beat. It is an outlet by which young children can begin to express their creative side in ways untapped by other academic disciplines and curricular components.

Music technology is important at the early grades because children of all ages possess an innate ability to express themselves through music. In essence, music allows children to celebrate the differences in culture and personality that are inherent amongst them (Chen-Hafteck and Zhuoya, 2008). An inherent value in incorporating music technology into the early technology curriculum rests in the ability of music to teach children to explore and to take risks (Chen-Hafteck and Zhuoya, 2008). With modern technology, children can play with different sounds combinations and rhythms to create unique and new creative pieces that demonstrate artistic expression. This knowledge can then spill over into other areas of the child' $s$ academic life as well.

One final area of importance that should be noted in terms of music technology curriculum is its unique ability to allow children to collaborate together, share experiences and create a finished project. Music requires children to focus and to concentrate. Correctly implemented music technology curriculum will enhance the ability of young children to remain disciplined and will 


\section{Ko and Chou}

greatly improve their self-esteem as they work with their classmates to produce different melodies and to implement artistic expression into their daily activities (Knight and LaGasse, 2012).

\section{Music Technology Curriculum and Young Children's Creative Capability}

Research demonstrates that certain curricular components in an educational setting can be effective in sparking a child' s creativity (Barbot and Lubart, 2012; Stephens, 2012). The fine arts are certainly a way to further accomplish this goal. Music technology curriculum can promote a sense of creativity within the classroom environment that might otherwise be lacking. At these stages of a child' s development, they love to explore and experiment with new concrete ideas and objects. While young children may have difficulty expressing themselves in the abstract realm, they can use music as a way to express their feelings and emotions (Stephens, 2012).

Music technology can be supplemented in any program to provide a well-balanced curriculum that encompasses many aspects of a child' $s$ intelligence and their ability to express and enhance their own creativity. Music education, when properly implemented at the early childhood level, can promote and foster the cognitive development of child. This means that music contributes to the knowledge, skills, attitudes, feeling, and senses that a child expresses as he/she develops. Young children often cannot express themselves verbally, but music provides them a creative outlet to accomplish that (Branscome, 2012 ; Nielson, 2013). It is in this real that the proper implementation of a music technology curriculum can be seen to have a positive effect on the creative development demonstrated by young children.

New music technology has been demonstrated to encourage creative musical engagement on the part of children. Crow (2012) found that, "Pupils engage in a range of musical learning through such [creative] interactions and that they value the processes and outcomes". Moving forward, it is advocated that music technology continue to expand in order to allow for even more musical creativity. Technology encourages exploration and it demonstrates ingenuity. By incorporating various pieces of electronic symmetry into the musical curriculum, early childhood education can continue to be a place where young children are able to explore their individualistic side (Crow, 2012). In light of the new technology that is available today, early childhood educators would be wise to continue to discover new ways that promote creativity in the classroom. The teacher incorporating music into the daily curriculum of the class is likely the teacher who enables this creative spark to take root in their students and is a classroom where invention and freedom of expression rule.

Music Technology Curriculum and Young Children' s Aesthetic Appreciation

If not properly moulded, children can begin to see the world from a one-dimensional perspective. They may begin to envision that the entire world thinks, acts, and feels just as they do (Hinchliff, 2008). Their family becomes the norm, their thoughts become baseline, and the colours and vibrancy of the world only serve to enhance their 
International Journal of Management, Economics and Social Sciences

own understanding of what it should look like. Part of the function of a well-rounded school curriculum is to ensure that this does not happen and that children grow in their appreciation of the beauty to be discovered in this big world. Music technology can foster a child' $s$ aesthetic understanding of the world in such a way that promotes the way they interpret the art, beauty, and creative expression that is available for all to touch and sample. (Barbot and Lubart, 2012).

Aesthetic appreciation is critically important to promote in young people, as it is a marker that determines their understanding of the world (Heines et al., 2011; Southcott and Crawford, 2011). When considering music technology, such appreciation can be developed as young children listen, respond, perform and compose various pieces. To begin, let us examine the ways that listening and responding to music can enhance a child' $s$ aesthetic appreciation of his or her surroundings moving forward.

Listening involves the eliciting of either a physical, verbal, emotional or cognitive response. Often we teach children to act on their own imagination, but we neglect to teach them the power of listening and responding to their surroundings. Music technology can accomplish this by encouraging students to play a piece of electronic music, be still for a few moments, and then give a response in one of the four critical developmental areas that epitomizes early childhood education (Chen-Hafteck and Zhuoya, 2008). Learning to appreciate the aesthetic beauty existent in the world does not happen quickly. The fine arts curriculum is designed to gradually nudge children towards this appreciation and to be able to express that through their words and actions.

Listening music over time produces a scaffolding effect that builds upon previous knowledge and experiences. Music technology curriculum provides children with the opportunity to listen to a range of music, both known and unknown to them, and then respond to each in turn. While listening the music, children can focus on a variety of sounds that the technology produces. Upon doing so, the child can then be encouraged to respond to what they have just heard by using their imagination and describing the sounds they just listened to and give their own interpretation. Over time, if properly implemented into the music classroom, young children can increase the precision with which they are able to listen and respond to all types of sounds and sources of information (Chen-Hafteck and Zhuoya, 2008).

Using a music technology curriculum to allow children to play music is yet another effective way to improve their aesthetic appreciation of nature (Hillier, 2011). The voice is the first and most obvious instrument a child comes into contact with, but it is certainly not the only means of performing. With current technology, even young children can begin to arrange pieces that have ethnic or cultural themes, or otherwise express their own feelings about a specific and assigned genre (Cole, 2011). The voice enables children to experience the joy of music. It is also as a result of the voice that other aspects of musical skills can be expanded upon by young children. Children first learn to perform by imitating others and mimicking their words and actions. This is 


\section{Ko and Chou}

evident during playtime where one can typically see young children acting out their favourite singer or group. Music technology encourages this by making it easier for children to perform and to listen back to what they have just mastered (Cole, 2011). Over time, they will not only be mimicking the sounds of others, but they will be performing their own creative and unique pieces based on their own individualized understanding of what music means to them.

The beauty of an early childhood music technology curriculum is that young children enjoy letting their imagination run wild. Not everyone, however, can play a musical instrument or makes sense out of rhythm and melody. This could be quite frustrating to a kid. Technology today, however, enables children to explore with various pieces of equipment, for their own chants and tunes (Demski, 2011). This can be done via homemade instruments, or in today' $s$ technologically driven classrooms, via computerassisted devices that mimic those same homemade instruments.

Children can also express their aesthetic appreciation of music through composition. We have already established that young children can become more creative and unique when encouraged by a curriculum rich in musical technology. Composing a piece of music continue this theme by providing young children with an outlet for self-expression (Stephens, 2012). Composing is not simply about the playing of a created musical piece. The composition side of music technology should involve each child listening to a variety of musical arrangements and then deciding which instruments, sounds, and rhythms best fit and capture the essence of what they would like to communicate (Standerfer, 2011). This further encourages children independence, while enabling them to grow in confidence that will likely carry over into other areas of their life.

\section{Music Technology Curriculum and Young Children' s Learning Motivation}

It can often be quite difficult today to motivate young children to excel in school. There are many areas of society today competing for the attention of children, and schools are often one of the last places where a child demonstrates motivation to do better. Mediocrity seems to rule the educational system of today, but it does not have to be that way. Music provides young children with an outlet where they can express themselves freely and openly. Music technology can enhance the quality of music being created and cause children to hear their creation instantly. Over time, this can serve to increase the motivation they have to do even better, due to the level of instant feedback that they receive (Elliott, 2012). Part of motivating a child involves encouraging them to get involved and active in the learning process. Music technology can accomplish this goal by providing an outlet and arena for creative and artistic expression (Jyrgensen, 2004; Susan, 2010). One aspect of an effective music technology curriculum is to create games and other experiences utilizing the musical genre to get children motivated and excited about what they are about to discover. This will enhance, over time, their musical knowledge, and lead to more skills and understanding than they previously had. Part of the curriculum, then, 
International Journal of Management, Economics and Social Sciences

should involve the elicitation of active responses and the encouragement of music making at each level of the early childhood grades.

\section{Music Technology Curriculum and Young Children's Character Education Development}

Early childhood education is about more than just reading, writing and arithmetic. Schools today are concerned with the whole child. They want young people to become positive contributors to society, to grow in their acceptance of all people, and to develop skills that enhance their overall character. One way to encourage this is to promote the whole-child (Carlisle, 2013; Susan, 2010). It is important to expose children to a variety of concepts and ideas so that they can learn to appreciate all that the world has to offer them (Andang' o and Mugo, 2007). Music encompasses different cultures and ways of life. Through musical accompaniment, individuals can visualize distant lands and grow to appreciate the differences in each of us that makes this world such a great place to live in.

The implementation of music technology is essential to creating a balanced curriculum that promotes the entire spectrum of childhood development. Having music as part of the curriculum allows children to grown in awareness and appreciation of his or her own unique culture. It also enables them to learn how to better accept others who may be different than they are and how to implement other cultural ideas in the shaping of their own worldview (Kersten, 2006). Music technology can assist a child in developing his or her own ethos (Gower and McDowall, 2012). As we know, an individual' $s$ ethos is his character. The term is used to describe the beliefs or ideals that guide the person to act. It further characterizes a community, nation, or individual ideology. All of this can be demonstrated through music. When children are exposed to a wide variety of cultural rhythms and beats, they begin to develop their own character while learning from the ethos of others. This can only serve to have a positive effect on their overall character development.

By way of example, let us consider Irish music. Longstanding traditions and cultural ideals from Ireland are expressed through its varied and storied musical history. Through a wide range of different musical instruments, young children can be figuratively transported to Ireland and experience their way of life. The music of Ireland represents the ways of life and the dreams and ambitions of countless musicians that have existed throughout time. Many of these traditions will be foreign to students studying music, so they serve as a way to enhance the character development of a child by exposing them to another perspective on life (Shore and Strasser, 2006).

There are many purposes that can be accomplished by enhancing the existing music technology curriculum present in a school. Music of the world can enhance the pleasure a child experiences when listening to a musical composition. It also promotes the need to remember patterns and melody, which can lead to a better understanding of people and their way of life. In addition, cultural music can encourage children to dance with energy and explore different ideas and notions about life that are existent in other cultures around the world. When 


\section{Ko and Chou}

such a curriculum is implemented in an educational setting, children can begin to develop their character while working individually or collectively. When working as a group, children learn to appreciate the music they are listening to and they can envision what other cultures are like. When a child is able to understand the differences that make us all unique, they will be much more likely to grow into adults that are tolerant and accepting of others who think and act differently (Thibeault, 2011). All of this can be discovered through a deeper appreciate of music and other areas of the fine arts curriculum.

In short, exposing young children to a variety of musical genres enhances their understanding of the world. It fosters an appreciation for others and can create a hunger and passion in children to explore other cultures even more fully. Music technology can promote an understanding of world history by encouraging children to use their imagination and to dive deeper into the mindset of people in distant lands. Technology enables us to do this in ways never before dreamed. Children can see native American dancing. They can play the various instruments in Ireland be interacting with them on a touch screen monitor, all the while manipulating sounds to replicate cultural music. Sky is truly the limit when considering how to design an early childhood music technology curriculum that reaches and encourages the whole child to emerge.

Effect of Independent Learning Ability and Attitude in Young Children

While much learning today does take place cooperatively, it is important that young children also develop an ability to learn and explore on their own. Educators strive enabling young people to develop an attitude whereby they feel comfortable in working independently, arriving at their own conclusions, and then demonstrating their work to others. The area of fine arts affords this opportunity, as children are encouraged to develop their style and form of expression (Batchelor and Bintz, 2012; Martin, 2012). If a positive attitude in this area is fostered, many children will see great improvement of their selfesteem as they work on their own on various tasks assigned in the music classroom.

As child gains independence, music can take on an entirely new meaning. Music technology activities that are developed in an early childhood education program can serve to develop an awareness and sensitivity to elements of music that are interconnected (Knight and LaGasse, 2012). This enables children, on their own, to explore such musical elements as pitch, texture, duration, tempo and dynamics in ways that could rarely be explored in a traditional classroom. Music technology enables young children to manipulate their own sounds, thereby gaining their own independence and freedom in the composition (Gordon, 1999).

Growth in musical independence also enables young children to gain a deeper understanding of music. They do this through self-discovery, which serves to enhance the validity of this particular proposition. Rather than asking children to verbally express what certain elements of a musical piece are, music technology enables them to display that to others on their own. They do that through their own expression in terms of singing and dancing (Shuler, 2012). 
International Journal of Management, Economics and Social Sciences

\section{CONCLUSION}

Present study concludes that music can be seen to play an important role in the educational, emotional and cognitive development of young people. It is important to understand that music fosters an appreciation of different cultures, encourages creativity and provides an outlet for freedom of expression. These three areas, combined with numerous others, explain the importance of an integrated music technology curriculum as part any early education program.

It is important that children gain an appreciation of different cultures and people existent in the world today. Society is more interconnected than ever, yet people in the world over possess different values and traditions.

These ideas are often best expressed through music. Music technology can bring countries to the classroom. People can also be encouraged to share their own understanding for their unique worldview in an effort to educate others around them. Music makes this all possible.

Finally, music is an outlet to express creativity. If children are not permitted to let their imagination run wild, they may be stymied and simply conform to whatever situation they are in as adults. In designing a curriculum that is focused on the fine arts, young children will become free to explore, design, and create at their own pace. This is critical to their development, both academically and cognitively.

\section{REFERENCES}

Andang' O, E. \& Mugo, J. (2007). Early childhood music education in Kenya: Between broad national policies and local realities. Arts Education Policy Review, 109(2): 43-52.

Barbot, B. \& Lubart, T. (2012). Creative thinking in music: Its nature and assessment through musical exploratory behaviors, Psychology of Aesthetics Creativity and the Arts, 6(3): 231-242.

Batchelor, K. \& Bintz, W. (2012). Hand-clap songs across the curriculum. Reading Teacher, 65(5): 341-345.

Berry, J. \& Allen, E. (2002). Faces to the window. Early Childhood Research \& Practice, 4(1): 1-10.

Branscome, E. (2012). The impact of education reform on music education: Paradigm shifts in music education curriculum. Arts Education Policy Review, 113(3): 112-118.

Carlisle, K. (2013). Steps toward gaining knowledge of world music pedagogy. General Music Today, 26(3): 7-12.

Chen-Hafteck, L. \& Zhuoya, X. (2008). Pulling the river: The interactions of local and global influences in Chinese early childhood music education. Arts Education Policy Review, 109(3): 9-16.

Church, E. (2001). The math in music and movement. Scholastic Early Childhood Today, 15(4): 38-40.

Cole, K. (2011). Brain-based research music advocacy. Music Educators Journal, 98(1): 26-35.

Crow, W. (2012). Remixing the music curriculum: The new technology, creativity, andperceptions of musicality in music education. PhD thesis, Institute of Education, University of London.

Demski, J. (2011). Music instruction goes digital. Education Digest, 76(7): 14-18.

Elliott, D. (2012). Music education for artistic citizenship. Music Educators Journal, 99(1): 21-28.

Gordon, E. (1999). All about audition and music aptitudes. Music Educators Journal, 86(2): 41-44.

Gower, L. \& McDowall, J. (2012). Interactive music video games and children's musical development. British Journal of Music Education, 29(1): 91-105.

Heines, J., Greher, G., Ruthmann, S. \& Reilly, B. (2011). Two approaches to interdisciplinary computing and music courses. Computer, 44(12): 25-32.

Hillier, E. (2011). Demystifying differentiation for the elementary music classroom. Music Educators Journal, 97(4): 49-53.

Hinchliff, G. (2008). Toddling toward technology: Computer use by very young children. Children \& Libraries, 6(3): 4749.

Hoffman, A. (2012). Performing our world: Affirming cultural diversity through music. Music Educators Journal, 98(4): 61-65.

Hoffman, S. (1991). Nurturing the expressive arts. Childhood Education, 68(1): 22-26.

Jyrgensen, H. (2004). Mapping music education research in Scandinavia. Psychology of Music, 32(3): 291-309.

Kersten, F. (2006). Inclusion of technology resources in early childhood music education. General Music Today, 20(1): 15-28.

Knight, A. \& LaGasse, A. (2012). Reconnecting to music technology: Looking back and looking forward. Music Therapy Perspectives, 30(2): 188-195.

Martin, J. (2012). Toward authentic electronic music in the curriculum: Connecting teaching to current compositional practices. International Journal of Music Education, 30(2): 120-132.

Nielson, L. (2013). Developing musical creativity: Student and teacher perceptions of a music technology curriculum. Applications of Research in Music Education, 31(2): 54-62.

Shore, R. \& Strasser, J. (2006). Music for their minds. Young Children, 61(2): 62-67.

Shuler, S. (2012). Core music education. Students' civil right. Music Educators Journal, 98(4): 7-15.

Southcott, J. \& Crawford, R. (2011). The intersections of curriculum development: Music, ICT and Australian music 
International Journal of Management, Economics and Social Sciences

education. Australasian Journal of Educational Technology, 27(1): 122-136.

Standerfer, S. (2011). Differentiation in the music classroom. Music Educators Journal, 97(4): 43-48.

Stephens, S. (2012). Music you can see. School Arts: The Art Education Magazine for Teachers, 112(1): 34-35.

Susan, H. (2010). The power of music: Its Impact on the intellectual, social, and personal development of children and young people. International Journal of Music Education, 28(3): 269-289.

Thibeault, M. (2011). Assessing your curriculum with the creative rights pyramid. Music Educators Journal, 98(1): 31-46.

Troutner, J. (2011). Cool curriculum options and tempting technology tools. Teacher Librarian, 39(2): 43-55. 